\title{
Thermal Hydraulic Analysis on the Water Lead Lithium Cooled Blanket for CFETR
}

\author{
Kecheng Jiang ${ }^{1}$, Yi Yu ${ }^{1,2}$, Xuebin Ma ${ }^{1}$, Qiuran Wu ${ }^{1,2}$, Lei Chen ${ }^{1}$, Songlin Liu ${ }^{1}$ and Kai Huang ${ }^{1, * \mathbb{D}}$ \\ 1 Institute of Plasma Physics, Hefei Institutes of Physical Science, Chinese Academy of Sciences, Hefei 230031, \\ China; jiangkecheng@ipp.ac.cn (K.J.); yi.yu@ipp.ac.cn (Y.Y.); maxuebin@ipp.ac.cn (X.M.); \\ qiuran.wu@ipp.ac.cn (Q.W.); chlei@ipp.ac.cn (L.C.); slliu@ipp.ac.cn (S.L.) \\ 2 University of Science and Technology of China, Hefei 230026, China \\ * Correspondence: huangkai@ipp.ac.cn
}

Citation: Jiang, K.; Yu, Y.; Ma, X.; Wu, Q.; Chen, L.; Liu, S.; Huang, K. Thermal Hydraulic Analysis on the Water Lead Lithium Cooled Blanket for CFETR. Energies 2021, 14, 6350. https://doi.org/10.3390/en14196350

Academic Editor: Hyungdae Kim

Received: 31 July 2021

Accepted: 17 September 2021

Published: 5 October 2021

Publisher's Note: MDPI stays neutral with regard to jurisdictional claims in published maps and institutional affiliations.

Copyright: (c) 2021 by the authors. Licensee MDPI, Basel, Switzerland. This article is an open access article distributed under the terms and conditions of the Creative Commons Attribution (CC BY) license (https:// creativecommons.org/licenses/by/ $4.0 /)$.

\begin{abstract}
A new type of Water Lead Lithium Cooled (WLLC) blanket that adopts the modular design scheme, water cooling the structure components, liquid $\mathrm{PbLi}$ as breeder and coolant, and $\mathrm{SiC}$ as the thermal insulator between $\mathrm{PbLi}$ and structures is under development as a candidate blanket concept for the Chinese Fusion Engineering Test Reactor (CFETR). Based on a poloidal-radial slice model, thermal hydraulic analysis is performed for this blanket to validate the feasibility of design goals. Results show that the present design can achieve the outlet temperature in the range of $600-700{ }^{\circ} \mathrm{C}$, with all the material temperatures safely below the upper limits. A series of sensitivity analyses are also carried out. It indicates that the thermal conductivity (TC) of $\mathrm{SiC}$ would have a significant influence on the temperature field, streamlines and pressure drop; that is, lower TC of SiC can maintain the temperature of $\mathrm{PbLi}$ at a high level, and induce an increased number of vortices in the liquid $\mathrm{PbLi}$ flow as well as a larger pressure drop. On this basis, the joint effects of the TC of $\mathrm{SiC}$ and inlet velocity on the performance of blanket thermal hydraulics are analyzed, then the so-called "attainable region" is proposed. Finally, optimization design studies are carried out by decreasing the width of the front channel. Comparison results show that the present design is the most reasonable.
\end{abstract}

Keywords: thermal hydraulic; WLLC blanket; CFETR

\section{Introduction}

The mission of the Chinese Fusion Engineering Test Reactor (CFETR) is to demonstrate fusion energy production on the basis of ITER's existing technologies [1]. The blanket surrounding the plasma is an essential component, which should achieve three main functions: reliable shielding performance, sufficient tritium breeding, and efficient heat removal for electricity production. Blanket concepts can be classified into solid and liquid blankets according to the physical form of functional materials [2-4]. The liquid blanket relies on the compound or alloy containing lithium as tritium breeder and neutron multiplier, which has inherent advantages, i.e., good geometric adaptability, possibility to bring the breeders out of the blanket for tritium extraction, and higher thermal conductivity, etc. [5]. The family of liquid breeders mainly comprises pure lithium, lead lithium (PbLi), and low melting point ternary $\mathrm{Pb}-\mathrm{Li}-\mathrm{X}$. Recently, the $\mathrm{PbLi}$ eutectic alloy has been widely used because of its much lower chemical reactivity with air and water, which can be used for blanket structure cooling.

Researchers have explored a variety of feasible liquid blankets, aiming at obtaining higher coolant temperatures for efficient electricity generation through reasonable structure and thermal hydraulic design. In some of the advanced conceptual designs [6-8], i.e., ARIES-AT, Tauro, and the He-Li-V blanket, the structure uses high-temperature resistant materials, such as ceramic composite $\left(\mathrm{SiC}_{\mathrm{f}} / \mathrm{SiC}\right)$ or vanadium alloy. $\mathrm{SiC}$ is attractive as it allows higher operation temperature and removes decay heat, alleviating the loss of coolant accident (LOCA) and loss of flow accident(LOFA). However, this material shows 
apparent deterioration in thermal and mechanical properties under neutron irradiation conditions, and it is challenging to bear the static and disruption pressure from liquid metal due to the low ductility. Besides, the manufacturing technology for both SiC and vanadium alloy is immature, and this limits industrial-scale applications. These problems may be overcome by using the mature Reduced Activation Ferritic Martensite (RAFM) steel as the structural material, which is cooled below $550{ }^{\circ} \mathrm{C}$ by gas or water. This blanket design is divided into self-cooled and separately cooled concepts, respectively, depending on the velocity level ( $\sim 10 \mathrm{~mm} / \mathrm{s}$ or $\sim 1 \mathrm{~mm} / \mathrm{s})$ of liquid PbLi. The self-cooled blanket uses PbLi as tritium carrier and coolant, which is circulated at a large velocity towards the external heat exchanger, thus the Magnetohydrodynamics (MHD) effect is inevitable. It needs flow channel inserts (FCI) acting as a thermal and electricity insulator between the PbLi and steel structures [9-11]. On the contrary, the separately cooled blanket adopts stagnant or slowly flowing PbLi only for tritium carrying, whereas the heat is removed by another coolant in the structural component, thus the MHD effects are not important. The WCLL and HCLL blankets $[12,13]$ are such examples.

In the liquid blanket design, researchers usually neglect the MHD effect and adopt commercial computation fluid dynamic (CFD) software to optimize the structure design and obtain preliminary thermal hydraulic results, then the MHD is further investigated. For example, E. Martelli established the sliced three-dimensional (3D) model based on the outboard equatorial plane, then adopted ANSYS CFX to evaluate the heat removal capacity of the first wall and breeder zone, and further optimize the cooling tube layout to simplify the structure [14]. Similarly, R. Boullon optimized the cooling channel design based on the 1/4 model of the HCLL blanket [15]. W. Li modified the system analysis code RELAP5/MOD3 by inserting into the governing equations the MHD pressure and heat transfer coefficient between PbLi and helium, then applied it to analyze the DFLL-TBM [16]. I. Fernández developed a 1D thermal hydraulic code, which can obtain the global design parameters for the outboard blanket. Besides, it is found that there appears to be buoyancydriven flow in the front poloidal channel due to the radially decreasing power heating [17]. W. Ni further theoretically studied the effects of strong buoyancy on flow and heat transfer characteristics in the front channel [18].

The water lead lithium cooled blanket (WLLC) is being under development as a candidate blanket concept for CFETR. It adopts the self-cooled design, which uses pressurized water $\left(15.5 \mathrm{MPa}, 285 / 325^{\circ} \mathrm{C}\right)$ removing heat from the structural components, and liquid $\mathrm{PbLi}$ at an inlet temperature of $460{ }^{\circ} \mathrm{C}$ flowing through the blanket to carry heat and tritium from the breeder zones. The temperature of the slowly moving $\mathrm{PbLi}$ finally approaches $600-700{ }^{\circ} \mathrm{C}$ for heat exchange. The present paper addresses the design feasibility of this WLLC blanket from the thermal hydraulic perspectives.

\section{Structural Design}

As shown in Figure 1, the CFETR blanket system consists of 16 sectors along the toroidal direction, and each sector includes three outboard and two inboard segments. To maintain the fusion machine conveniently by remote handling and reduce the electromagnetic force, the blanket layout adopts a multi-modular segment (MMS) design. The outboard and inboard segments have 5 and 6 blanket modules, respectively. The detailed structure design of outboard module $3 \#$ located on the equatorial plane is shown in Figure 2.

The blanket uses RAFM steel as the structural material, and the main components include the first wall (FW), cooling plates (CPs), stiffening plates (SPs), and cover plates. These components share the same manifolds, which makes water flowing into them in parallel. The FW is a U-shaped structure in which the coolant water passes through the channels along the radial-toroidal direction, and the flowing direction between adjacent channels is set opposite to alleviate the mechanical stress. Moreover, there is a layer of tungsten coating on the FW to protect it from plasma erosion and corrosion. The CPs are designed as an intersecting " 7 " shape, and it collaborates with the SPs to form the 5 
(toroidal) $\times 3$ (radial) $\mathrm{PbLi}$ channels. The PbLi flows upwards, then turns into two separate channels, finally converges before the manifolds. To reduce the MHD effects and increase the outlet temperature of $\mathrm{PbLi}$, the SiC layer acting as a thermal and electrical insulator is inserted between $\mathrm{PbLi}$ and the structural steel. A gap filling with $\mathrm{PbLi}$ between the SiC and structural steel is preserved on purpose, which can avoid structural stress resulting from the direct contact between two different materials. Between the adjacent SPs, $\mathrm{Be}_{12} \mathrm{Ti}$ blocks are inserted to further enhance the capability of neutron multiplying.

The design feature must satisfy multiple requirements because there are strong coupling effects between neutronics and thermal hydraulics. For example, neutronic transportation creates nuclear heat on the structure, and thermal hydraulic analysis is based on the power distribution. On the contrary, thermal hydraulic optimization on the structure arrangement will change the neutronics performance, i.e., TBR and nuclear heating [19]. There are several design criteria for thermal hydraulic analysis, as shown in Table 1 . In principle, under the condition that the material temperature is below the upper limit, the outlet temperature of PbLi should be as high as possible $\left(600-700{ }^{\circ} \mathrm{C}\right)$ to achieve efficient power conversion, which is the key objective for blanket design. Besides, the interface temperature between $\mathrm{RAFM}$ steel and $\mathrm{PbLi}$ in the gap is controlled by coolant water, and it should be kept below $480{ }^{\circ} \mathrm{C}$ to prevent corrosion acceleration.

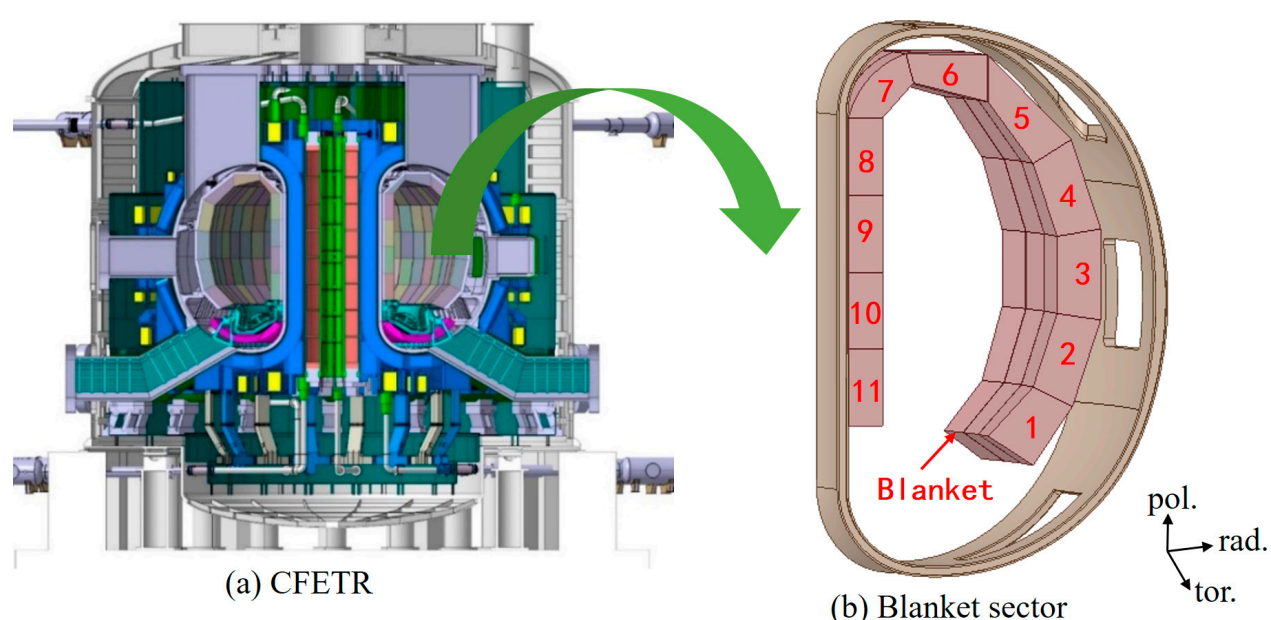

Figure 1. CFETR and blanket layout.

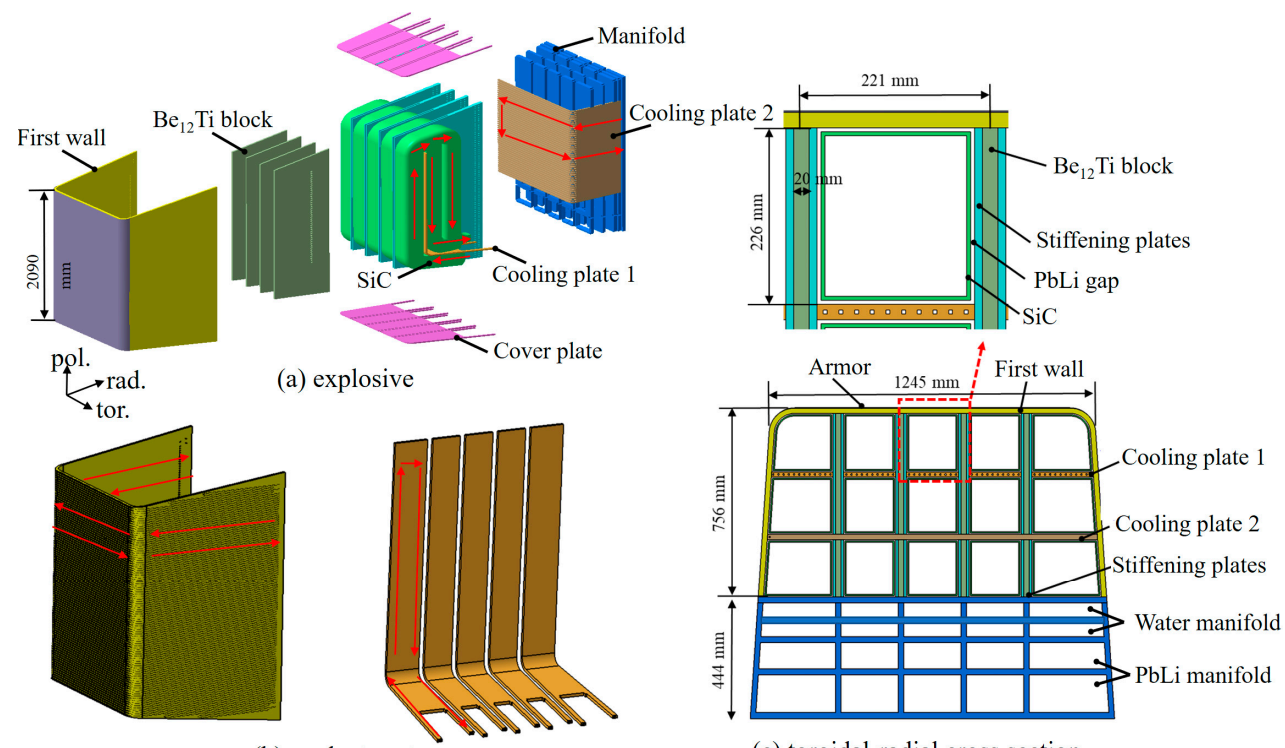

(b) coolant routes

(c) toroidal-radial cross section

Figure 2. Structural design of the WLLC blanket (module 3\#). 
Table 1. Design criteria for thermal hydraulics.

\begin{tabular}{cc}
\hline Items & Temp. Limit $\left({ }^{\circ} \mathbf{C}\right)$ \\
\hline Water & inlet: 285/outlet: 325 \\
$\mathrm{PbLi}$ & inlet: $460 /$ outlet: $600-700$ \\
$\mathrm{Be}_{12} \mathrm{Ti}$ & 900 \\
$\mathrm{RAFM}$ & 500 \\
$\mathrm{SiC}$ & 1000 \\
PbLi-RAFM interface & 480 \\
\hline
\end{tabular}

\section{Numerical Model}

The commercial computational fluid dynamic (CFD) code FLUENT is adopted to perform the analyses. In all the analyses, the minimum Reynolds number under the velocity of $0.03 \mathrm{~m} / \mathrm{s}$ is 41,574 , and it is already within the turbulent region. The SST $k-\omega$ model is used to model turbulence as it is capable of simulating the internal channel flow separation against the pressure gradient, which is a common phenomenon in this WLLC model. Since we only consider the performance of the blanket steady-state operation, the steady-state model is employed. And the pressure-based solver is used. Besides, the PbLi flow has an uneven distribution of nuclear heating along the radial direction, and it is subjected to the gravity force, thus there are strong buoyancy-driven effects. We use the Boussinesq approximation to model the thermal convection equation, as given in

$$
\rho_{0} \frac{\partial u_{i}}{\partial t}+\rho_{0} u_{j} \frac{u_{i}}{x_{j}}=-\frac{\partial p^{\prime}}{\partial x_{i}}+u \frac{\partial^{2} u_{i}}{\partial x_{j}^{2}}-\alpha \rho_{0} g_{i}\left(T-T_{0}\right)
$$

where $\alpha$ is the thermal expansion coefficient of the coolant, $1 /{ }^{\circ} \mathrm{C} ; \rho_{0}$ and $T_{0}$ is reference density $\left(\mathrm{kg} / \mathrm{m}^{3}\right)$ and temperature $\left({ }^{\circ} \mathrm{C}\right)$, respectively. This approximation considers the density change caused by temperature change and applies it to adjust the momentum governing equation. By employing this approximation, the buoyancy-driven flow can be simulated.

In order to obtain the preliminary thermal hydraulic results for optimization with improved calculation efficiency, a 2D model is developed and adopted for the analysis (Figure 3). This model is a poloidal and radial slice, which is located on the toroidal central plane based on the 3D blanket model. The heat flux from plasma is set as $0.5 \mathrm{MW} / \mathrm{m}^{2}$. The temperature on the backplate is fixed as $285^{\circ} \mathrm{C}$ since it directly contacts the inlet manifold containing water. A heat-transfer boundary condition of the third kind derived from Newton's law of cooling, which includes the bulk temperature of coolant and heat transfer coefficient (HTC), is applied. The bulk temperature in each component and the corresponding HTC values $[20,21]$ used in the calculation are listed in Table 2. The nuclear power distribution along the radial direction is obtained using a 3D MCNP analysis, and the results are normalized to $1.5 \mathrm{GW}$ fusion power. Meanwhile, the power distribution is fitted as a user defined function (UDF) implemented into the FLUENT code, which allows each mesh cell to have a more precise nuclear heating source term. The gravity force is set as the actual operation condition. Besides, the thermal properties of materials are listed in Table 3. 


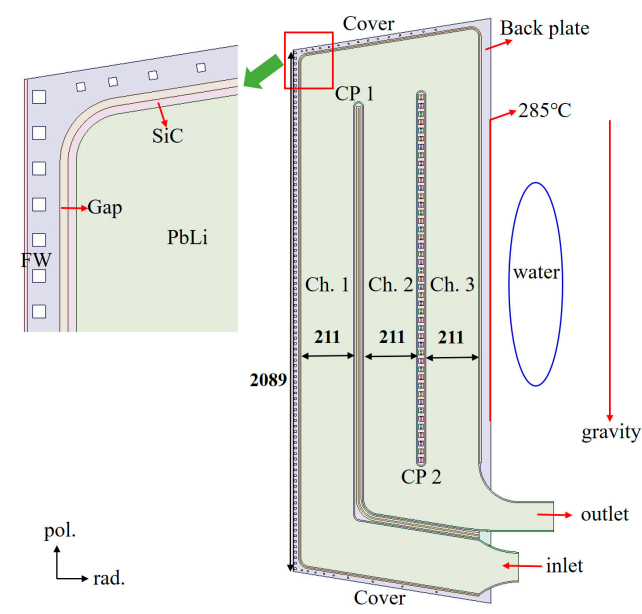

(a)

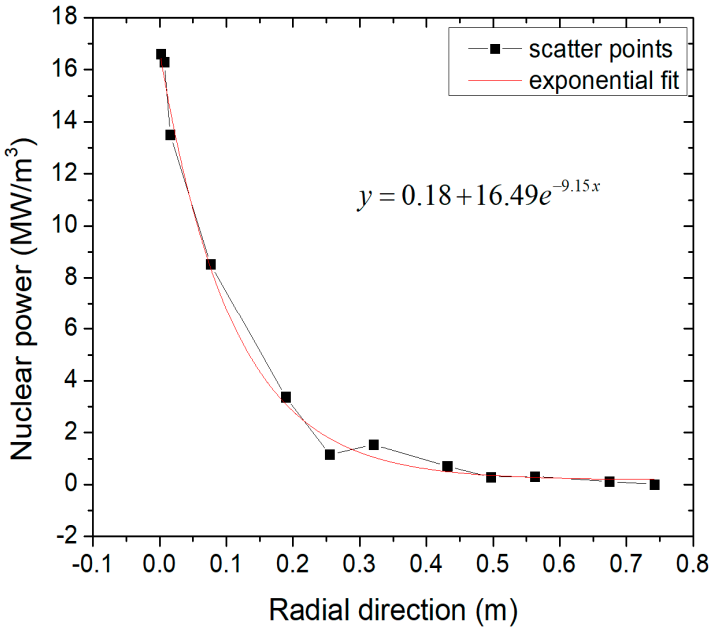

(b)

Figure 3. (a) Two dimensional numerical model; (b) radial power distribution.

Table 2. Boundary conditions for numerical analysis [20,21].

\begin{tabular}{|c|c|c|}
\hline Components & Temperature $\left({ }^{\circ} \mathrm{C}\right)$ & HTC $\left(\times 10^{4} \mathrm{~W} / \mathrm{m}^{2} \cdot{ }^{\circ} \mathrm{C}\right)$ \\
\hline $\mathrm{CP} 1$ & 290 & 1.0 \\
\hline $\mathrm{CP} 2$ & 290 & 1.0 \\
\hline Cover & 290 & 1.0 \\
\hline FW & 300 & 1.9 \\
\hline
\end{tabular}

Table 3. Thermal properties of materials.

\begin{tabular}{cc}
\hline Materials & Thermal Properties \\
\hline Tungsten [22] & $\lambda=207.98-0.136 \mathrm{~T}+5.469 \times 10^{-5} \mathrm{~T}^{2}-7.835 \times 10^{-9} \mathrm{~T}^{3}$ \\
\hline RAFM [23] & $\lambda=32.5$ \\
\hline $\operatorname{SiC}[24]$ & $\lambda=3.5$ \\
\hline $\operatorname{PbLi~[25]~}$ & $\rho=10520-1.189 \mathrm{~T}$ \\
& $\mu=0.00914-1.77459 \times 10^{-5} \mathrm{~T}+9.5521 \times 10^{-9} \mathrm{~T}^{2}$ \\
& $C_{p}=194.74-9 \times 10^{-3} \mathrm{~T}$ \\
& $\alpha_{\mathrm{v}}=\left(11.221+1.531 \times 10^{-3} \cdot \mathrm{T}\right) \times 10^{-5}[26]$ \\
\hline
\end{tabular}

$T$ : temperature, $\mathrm{K} ; \lambda$ : thermal conductivity, $\mathrm{W} /(\mathrm{m} \cdot \mathrm{K}) ; \rho$ : density, $\mathrm{kg} / \mathrm{m}^{3} ; \mu$ : dynamic viscosity, Pa.s; $\mathrm{C} p$ : specific heat, $\mathrm{J} /(\mathrm{kg} \cdot \mathrm{K})$.

The model uses the mixed structured and unstructured meshes, as shown in Figure 4. By adjusting the mesh size in the solid and fluid domain, mesh independence verification is performed based on the typical thermal hydraulic model (see Section 4.1), as shown in Figure 5. It indicates that the element number of 179,090 is already enough to obtain the precise results, and there is only a temperature increment of $0.35{ }^{\circ} \mathrm{C}$ if the element number increases to 332,139 . Therefore, the mesh layout with 179,090 elements is adopted for the analyses in this paper. The mesh size of the solid and fluid domains is $2.5 \mathrm{~mm}$ and $5.0 \mathrm{~mm}$, respectively. In the boundary layer, the growth rate is 1.4, and there are 18 layers. 


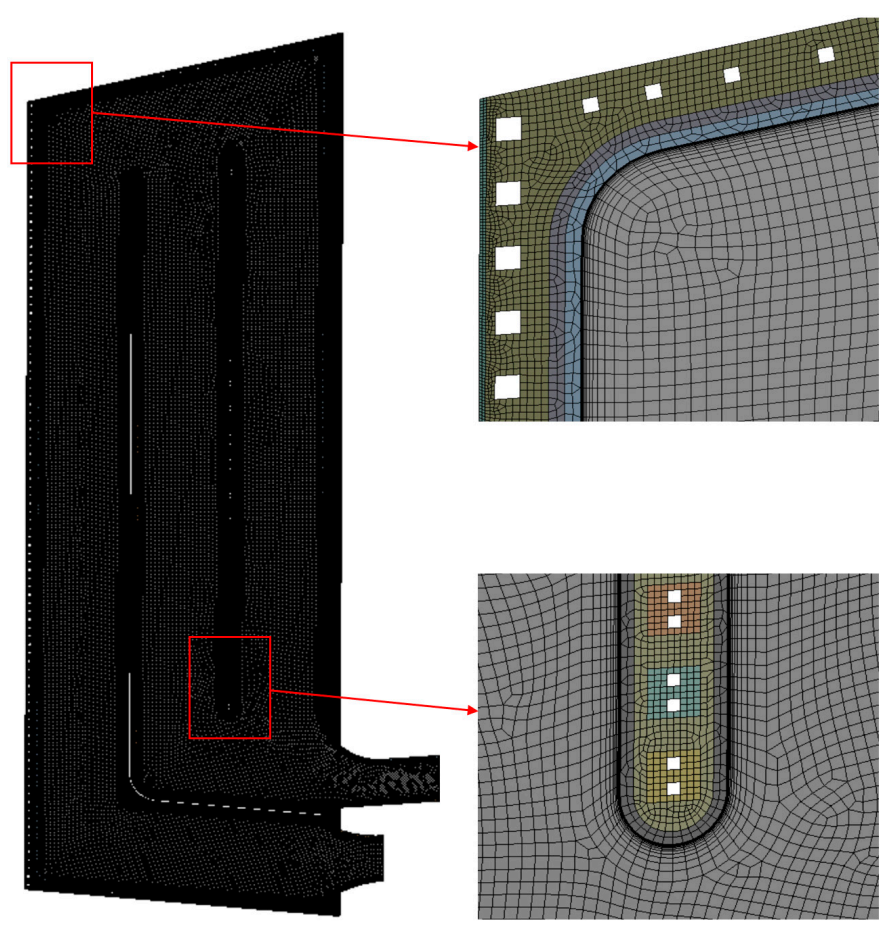

Figure 4. Mesh arrangement.

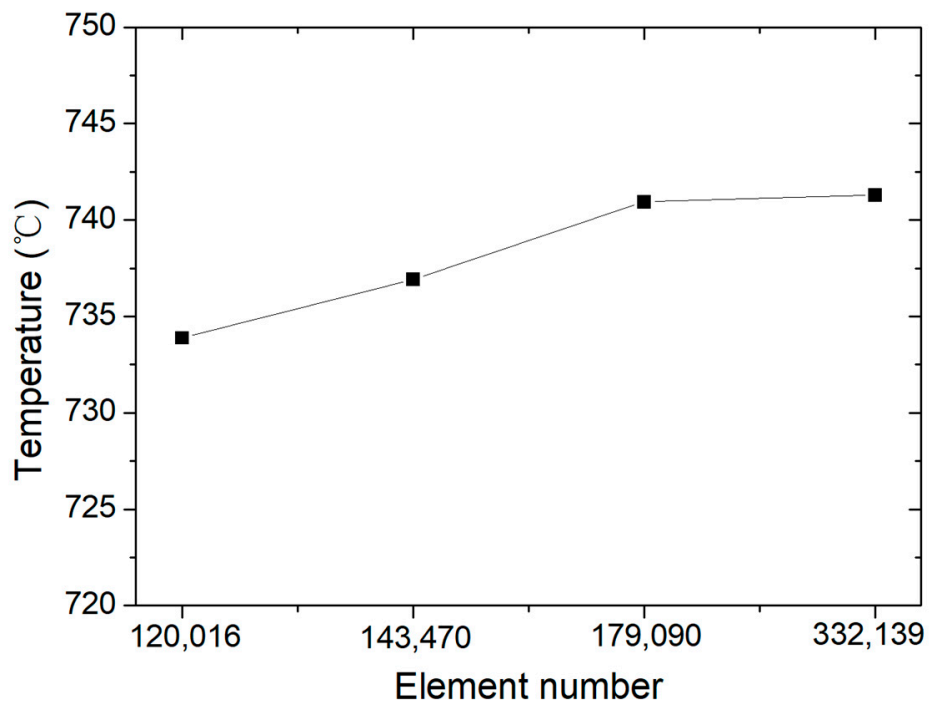

Figure 5. Mesh independence verification.

\section{Results and Discussion}

\subsection{Typical Thermal Hydraulic Results}

The thermal hydraulic results of a typical model which can achieve a satisfactory outlet temperature are summarized in Table 4 . The thermal conductivity of $\mathrm{SiC}$ has considerable effects on heat transfer between $\mathrm{PbLi}$ and water, and former researchers optimized this parameter as $3.5 \mathrm{~W} /\left(\mathrm{m} \cdot{ }^{\circ} \mathrm{C}\right)$ to have better performance of thermal and electrical insulation [24]. During the analysis, the inlet velocity of PbLi is iteratively adjusted. The velocity of $0.05 \mathrm{~m} / \mathrm{s}$ is able to elevate the outlet PbLi temperature to as high as $612.85^{\circ} \mathrm{C}$ that is within the targeting range of $600-700{ }^{\circ} \mathrm{C}$. However, this is at the cost of a $1.79 \mathrm{kPa}$ pressure drop. Moreover, all the material temperatures stay below the upper limits, as well as the interface in the gap between PbLi and the RAFM steel. Among the 
materials, $\mathrm{PbLi}$ has the highest temperature since it enters at a relatively high temperature aiming at better power conversion efficiency.

Table 4. Results of typical thermal hydraulic analysis cases.

\begin{tabular}{|c|c|c|c|c|c|c|c|c|}
\hline \multirow{2}{*}{$\begin{array}{c}\lambda_{\mathrm{SiC}} \\
\left(\mathrm{W} / \mathrm{m} \cdot{ }^{\circ} \mathrm{C}\right)\end{array}$} & \multirow{2}{*}{$\begin{array}{l}\text { Velocity } \\
(\mathrm{m} / \mathrm{s})\end{array}$} & \multicolumn{6}{|c|}{ Max. Temperature $\left({ }^{\circ} \mathrm{C}\right)$} & \multirow{2}{*}{$\Delta P(\mathrm{kPa})$} \\
\hline & & Tungsten & RAFM & $\mathrm{SiC}$ & PbLi & Interface & Outlet (Ave.) & \\
\hline 3.5 & 0.05 & 468.83 & 468.83 & 704.89 & 740.95 & 468.83 & 612.85 & 1.79 \\
\hline
\end{tabular}

\subsubsection{Temperature Field}

The temperature field of the entire model is shown in Figure 6a. As can be seen, the $\mathrm{PbLi}$ entered Channel 1 and is heated continuously to the upper location, where the peak temperature of $741{ }^{\circ} \mathrm{C}$ takes place. However, when it splits and then flows into Channel 2 and 3 , the temperature decreases rapidly to the average outlet temperature of $612.85^{\circ} \mathrm{C}$. This is because the nuclear heat source in the back zone of the blanket is lower than the front, and CP2 further cools the PbLi. Besides, the inlet channel with a low temperature of $460{ }^{\circ} \mathrm{C}$ connects directly with the outlet channel. Heat conduction between the inlet and outlet channels brings additional cooling effects.

Along the radial direction through point $A$, as shown in Figure $6 b$, the temperature of $\mathrm{PbLi}$ in each channel remains at a high level, and the distribution in most areas is relatively uniform, but it decreases rapidly near the CPs because of the strong cooling effects. In Channel 1, the temperature in the front zone is slightly higher due to the larger heating source, but it is not apparent since the coolant velocity decreases along the radial direction (Figure 7). As shown in Figure 6d of the FW, although the tungsten armor faces high heat flux from the plasma, the peak temperature is located at the breeder side for the reason that the PbLi contains larger amount of heat. Because the FW is cooled by water flowing through the embedded channels, sources including the plasma and breeder deposit heat into the FW coolant from both directions. This phenomenon can be understood from the radial temperature distribution, in which it decreases from armor to the channel at first, then increases to the $\mathrm{SiC}$ side. In Channel 1 and 2 , the temperature difference $\left(T_{1}-T_{0}\right)$ between the mainstream and channel wall is $50{ }^{\circ} \mathrm{C}$ and $125^{\circ} \mathrm{C}$, respectively. Thus, the Grashof number Gr can be calculated by Equation (2), as $3.3 \times 10^{10}$ and $8.3 \times 10^{10}$.

$$
G r=\frac{\alpha g\left(T_{1}-T_{0}\right) l^{3}}{v^{2}}
$$

where $\alpha$ is the volumetric thermal expansion coefficient, $1 / \mathrm{K} ; g$ is the gravity force, $\mathrm{m} / \mathrm{s}^{2} ; \mathrm{l}$ is the characteristic length, $\mathrm{m} ; v$ is kinematic viscosity, $\mathrm{m}^{2} / \mathrm{s}$. 


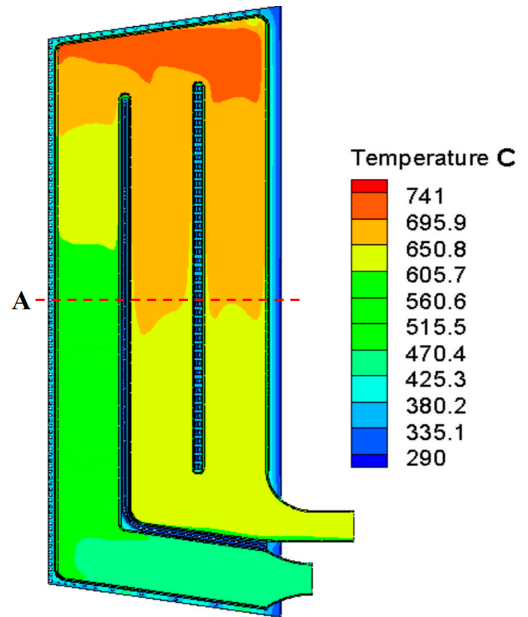

(a)

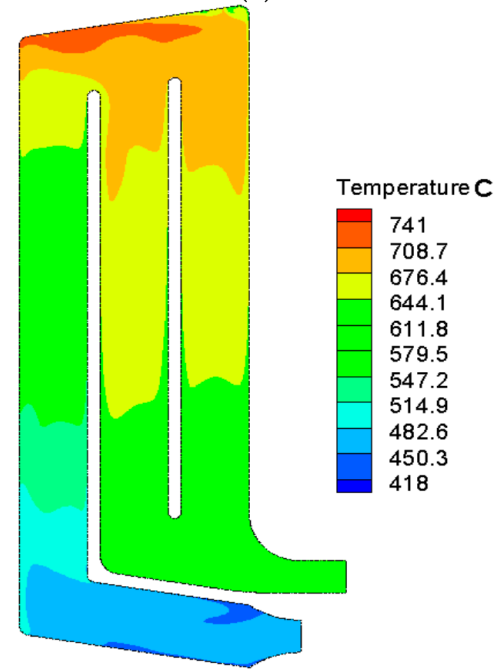

(c)

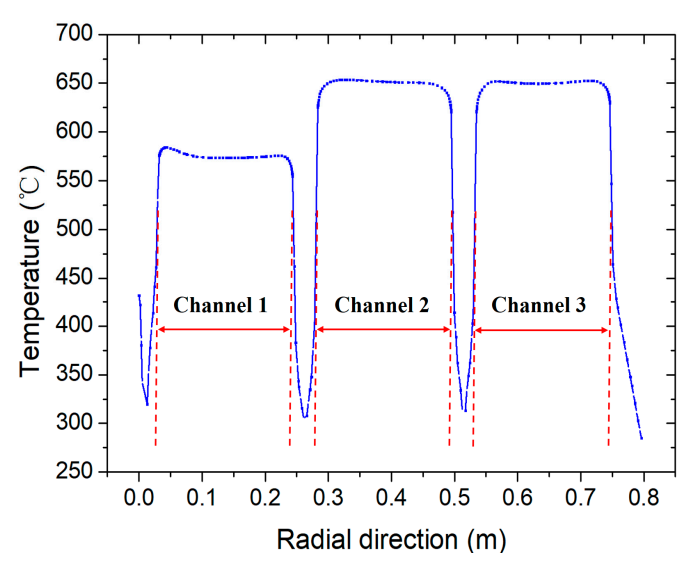

(b)

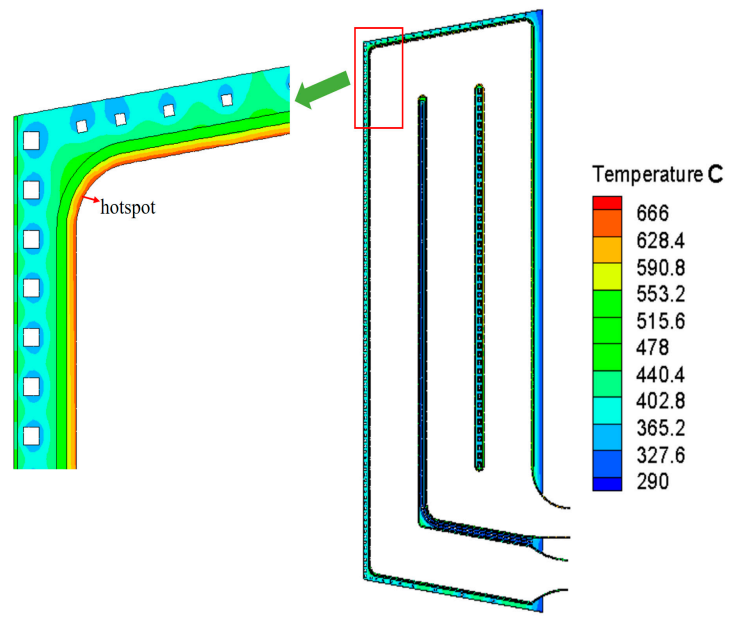

(d)

Figure 6. Temperature contour (a) entire model; (b) radial temperature distribution; (c) PbLi; (d) FW, gap and SiC.

\subsubsection{Velocity Field}

The flow velocity field is presented in Figure 7 , in which the velocity magnitude is synthesized by $x$ and $y$ velocities. It shows that the velocity near the channel wall is relatively larger, and a considerable number of vortices emerge nearby. This is closely related to the geometry design, gravity effects, and radial distribution of heating power. Take Channel 1 for example, PbLi flows into a nozzle with a sudden enlargement that causes larger velocity at the bottom of the radial pipe, which induces vortices. When it turns into the poloidal channel, the velocity near the front wall becomes significantly larger due to the centrifugal force, and it reduces sharply along the radial direction yet increases again since there are vortices caused by the different velocity gradients in the same channel. In Channel 1 and 2, because the poloidal temperature difference is $130{ }^{\circ} \mathrm{C}$, it brings about buoyancy lift due to the density difference. Therefore, vortices in the two channels show more complicated patterns. A vortex appears in the middle of the channel, which blocks the coolant flow, thus the velocity near the channel wall becomes larger. Furthermore, the velocity magnitude along the radial direction in Figure 7c shows that the mass flow in Channel 2 is smaller, which indicates that the natural convection dominates the flow field. This explains why the number of vortices in this channel is greater. It should be emphasized that vortices are to be avoided in liquid blankets because they may increase the momentum dissipation and further increase the pressure drop, which can reduce the power conversion efficiency. 


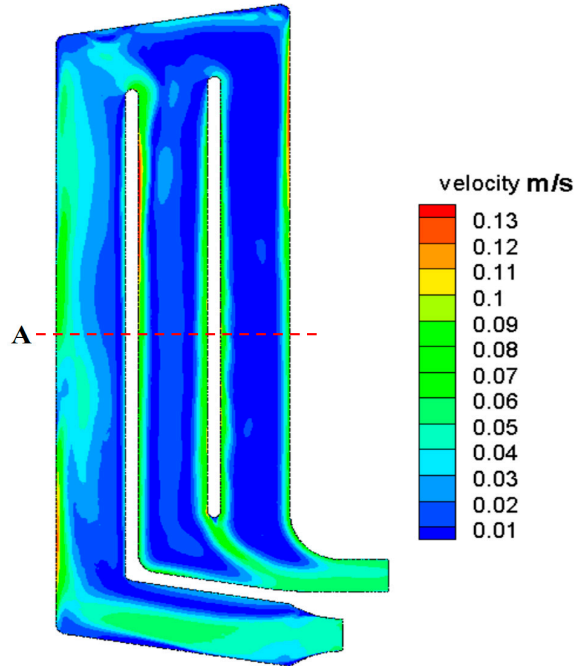

(a)

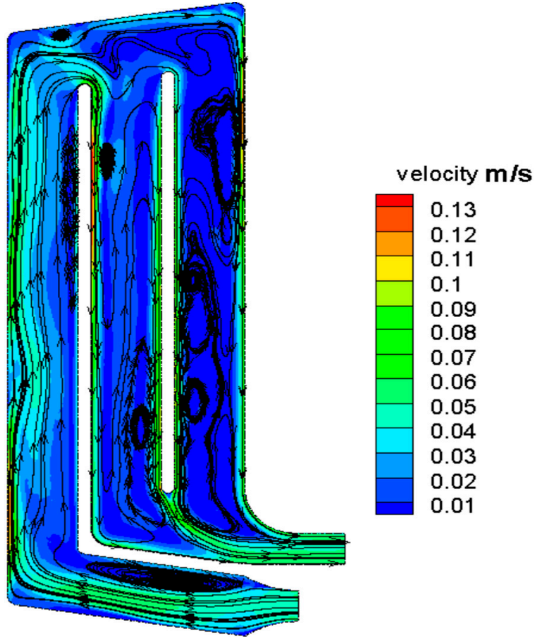

(b)

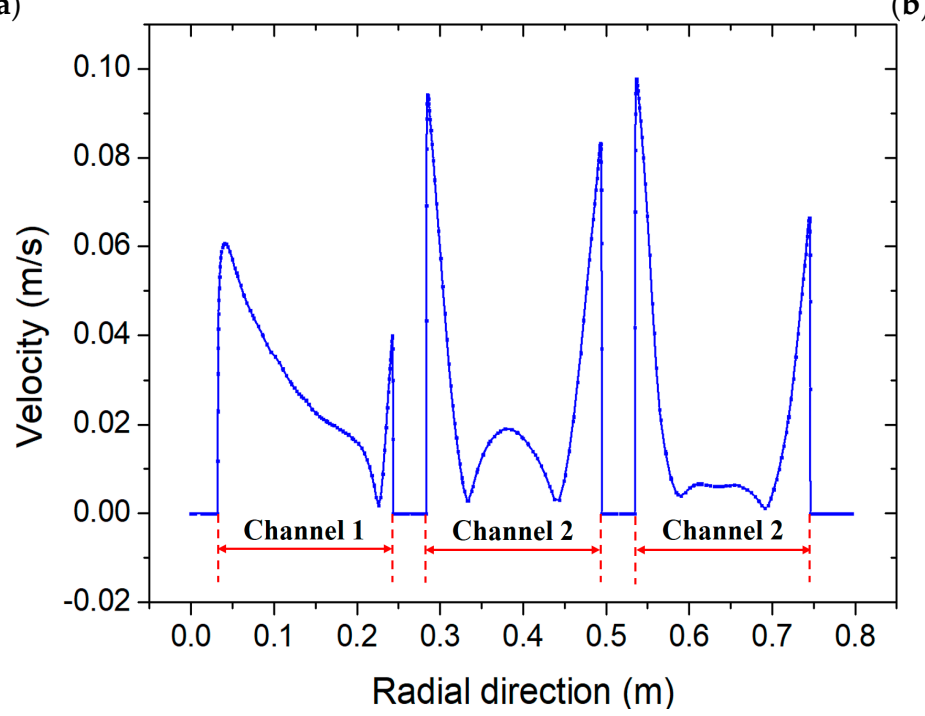

(c)

Figure 7. Velocity field (a) contour of magnitude; (b) streamline; (c) radial distribution of velocity magnitude.

\subsection{Sensitivity Analysis}

In the WLLC blanket design, the temperature of coolant water in the embedded channels inside the structural components is significantly lower than that of the flowing $\mathrm{PbLi}$, in order to prevent the RAFM steel from exceeding the upper limit. Hence, the heat transfers from $\mathrm{PbLi}$ to water. The $\mathrm{SiC}$ is inserted between $\mathrm{PbLi}$ and water to insulate heat. Basically, the thermal conductivity of SiC determines the heat transfer ability of this material. As $\mathrm{SiC}$ is a type of synthetic composite material, its thermal properties can be changed. Therefore, it is necessary to study the effects of thermal conductivity and coolant inlet velocity on the performance of thermal hydraulics.

\subsubsection{The Effects of SiC Thermal Conductivity}

In this sensitivity analysis, the thermal conductivity of $\mathrm{SiC}$ ranges from $1.0 \mathrm{~W} /(\mathrm{m} \cdot \mathrm{K})$ to $10.0 \mathrm{~W} /(\mathrm{m} \cdot \mathrm{K})$, while the velocity of $\mathrm{PbLi}$ is kept constant. The variation of maximum temperature and coolant pressure drop for all materials is plotted in Figures 8 and 9 . As the $\mathrm{TC}$ of $\mathrm{SiC}$ increases, the insulation performance of $\mathrm{SiC}$ deteriorates, and this causes more heat losses from $\mathrm{PbLi}$ to the structure materials, i.e., tungsten and RAFM. Therefore, the temperature of $\mathrm{PbLi}$ and $\mathrm{SiC}$ was decreasing, as well as the outlet temperature, while the temperature of tungsten and RAFM changes in the opposite way. When TC increases from 
$1.0 \mathrm{~W} /(\mathrm{m} \cdot \mathrm{K})$ to $10.0 \mathrm{~W} /(\mathrm{m} \cdot \mathrm{K})$, the temperature of PbLi reduces by $120^{\circ} \mathrm{C}$. As mentioned above, the temperature of the FW on the breeder side is higher, and it decreases along the reversed radial direction. Therefore, the hotspot appears at the interface between $\mathrm{PbLi}$ and RAFM, thus there is no difference in peak temperatures between RAFM and the interface. The temperature rise for the RAFM steel is $60{ }^{\circ} \mathrm{C}$, but it is only $5^{\circ} \mathrm{C}$ for tungsten because the distance to $\mathrm{PbLi}$ is farther. The outlet temperature for $\mathrm{TC}$ of $\mathrm{SiC}$ at $4.0 \mathrm{~W} /(\mathrm{m} \cdot \mathrm{K})$ is $603{ }^{\circ} \mathrm{C}$, and it will not satisfy the requirement (outlet $\mathrm{T} \geq 60{ }^{\circ} \mathrm{C}$ ) when the $\mathrm{TC}$ of $\mathrm{SiC}$ increases further.

Keeping the coolant velocity constant, the pressure drop is also significantly affected by the TC of $\mathrm{SiC}$, as it decreases by almost $90 \%$ when the TC increases from $1.0 \mathrm{~W} /(\mathrm{m} \cdot \mathrm{K})$ to $10.0 \mathrm{~W} /(\mathrm{m} \cdot \mathrm{K})$. This can be clarified from the contour of streamlines, as shown in Figure 10. As the temperature at the upper location becomes larger when TC decreases, the temperature difference term $\Delta T$ in Equation (2) becomes larger since the inlet temperature is the same. Thus, the buoyancy effects will be apparent and induce more vortexes. This will cause large momentum loss and pressure drop. However, the outlet temperature will be lower. And a compromise should be made among these design parameters.

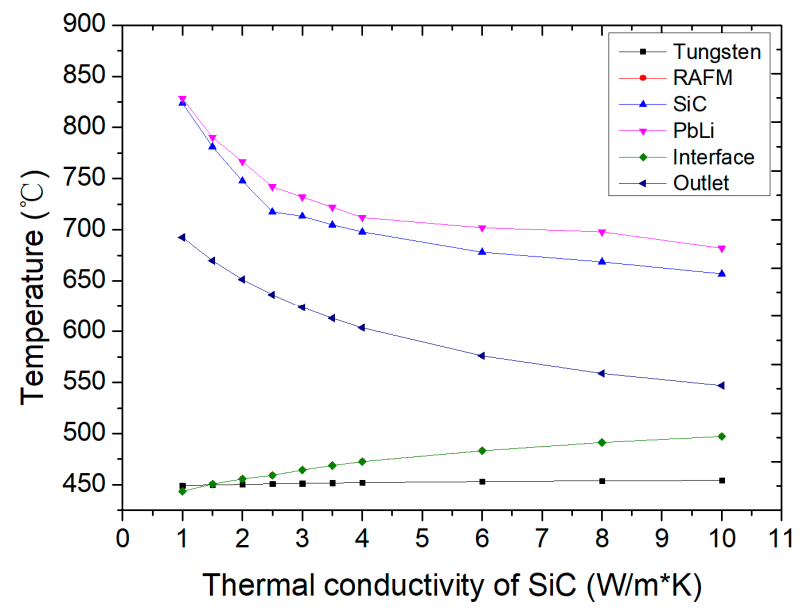

Figure 8. Variation of maximum temperature for different thermal conductivity of SiC.

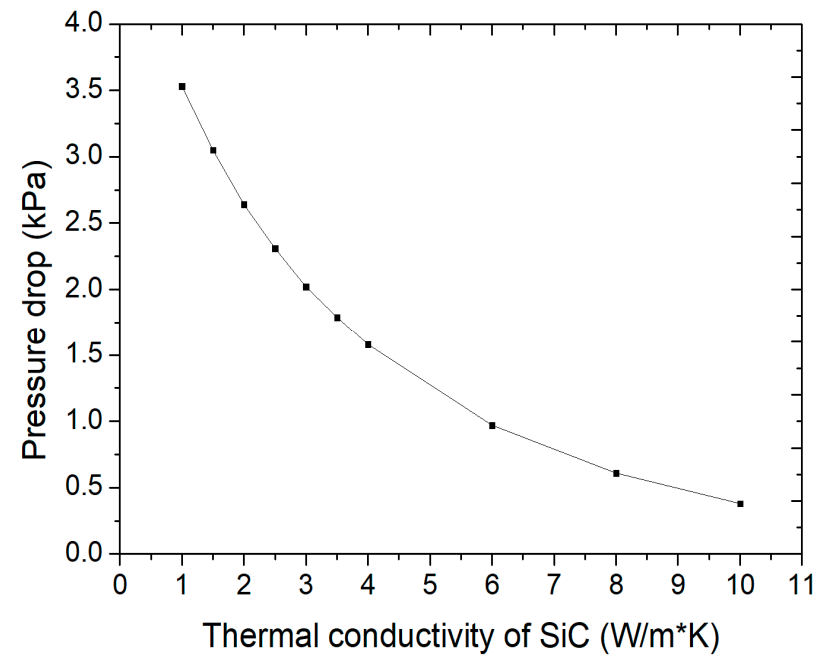

Figure 9. Variation of pressure drop for different thermal conductivity of $\mathrm{SiC}$. 


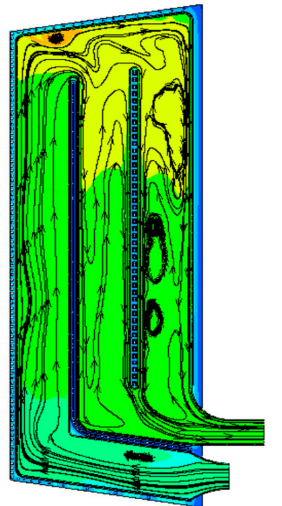

(a)

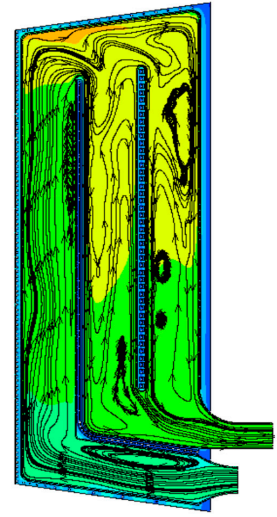

(b)

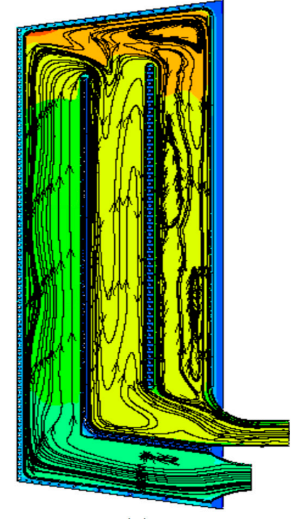

(c)

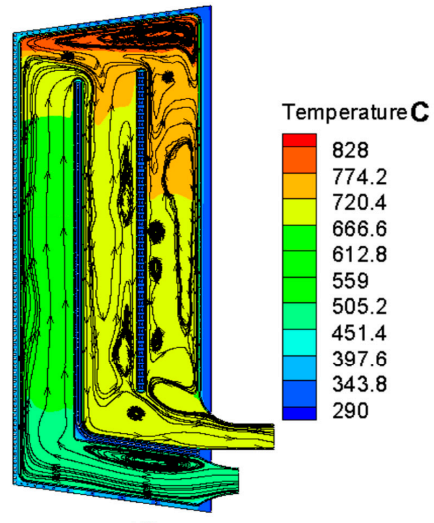

(d)

Figure 10. Contour of temperature and streamline for different thermal conductivity of $\mathrm{SiC}(\mathbf{a}) 3.5 \mathrm{~W} /(\mathrm{m} \cdot \mathrm{K})$; (b) $2.5 \mathrm{~W} /(\mathrm{m} \cdot \mathrm{K})$; (c) $1.5 \mathrm{~W} /(\mathrm{m} \cdot \mathrm{K}) ;(\mathrm{d}) 1.0 \mathrm{~W} /(\mathrm{m} \cdot \mathrm{K})$.

As shown in Figures 11 and 12, the effects of the TC of SiC on thermal hydraulics can also be further understood through the contour of streamlines. For different TCs, the general distribution of velocity magnitude remains alike, in which the velocity near the channel wall is still larger. Along the radial direction, it can be seen that there is no profound difference of velocity distribution in Channel 1 . However, as the TC of SiC decreases, the vortex at the upper location becames stronger, which blocks the coolant from flowing into Channel 3. Because the total mass flow rate is unchanged, this results in more PbLi entering Channel 2. When the TC of $\mathrm{SiC}$ decreases from $3.5 \mathrm{~W} /(\mathrm{m} \cdot \mathrm{K})$ to $1.0 \mathrm{~W} /(\mathrm{m} \cdot \mathrm{K})$, the velocity in Channel 2 increases by $40 \%$. This trend is opposite for Channel 3 .

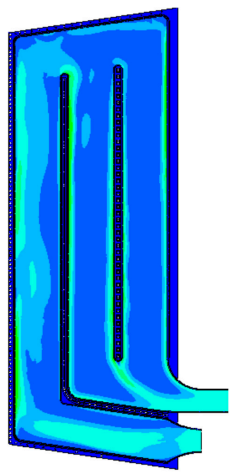

(a)

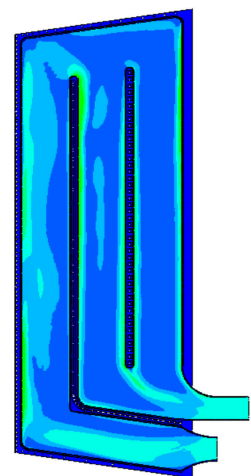

(b)

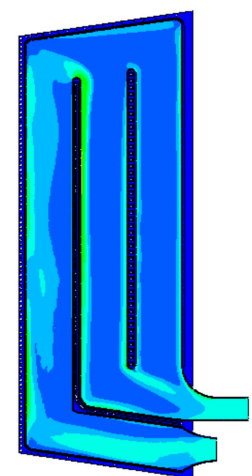

(c)

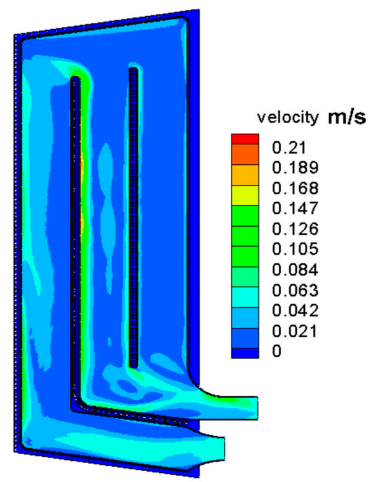

(d)

Figure 11. Contour of velocity magnitude for different thermal conductivity of $\mathrm{SiC}(\mathrm{a}) 3.5 \mathrm{~W} /(\mathrm{m} \cdot \mathrm{K})$; (b) $2.5 \mathrm{~W} /(\mathrm{m} \cdot \mathrm{K})$; (c) $1.5 \mathrm{~W} /(\mathrm{m} \cdot \mathrm{K})$; (d) $1.0 \mathrm{~W} /(\mathrm{m} \cdot \mathrm{K})$.

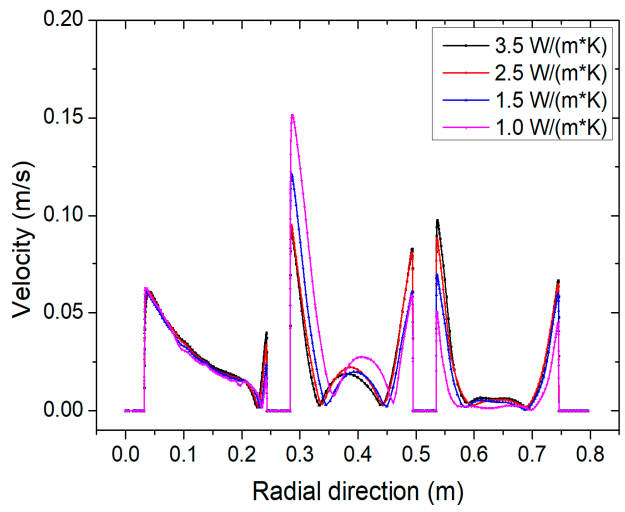

Figure 12. Radial distribution of velocity magnitude for different thermal conductivity of SiC. 


\subsubsection{The Effects of Coolant Velocity}

In the sensitivity analysis regarding coolant velocity, the TC of $\mathrm{SiC}$ is kept constant as $3.5 \mathrm{~W} /(\mathrm{m} \cdot \mathrm{K})$, while the coolant inlet velocity ranges from $0.03 \mathrm{~m} / \mathrm{s}$ to $0.12 \mathrm{~m} / \mathrm{s}$. As shown in Figures 13 and 14, increasing velocity can significantly reduce the material temperature, especially for $\mathrm{PbLi}$ and $\mathrm{SiC}$. For the outlet temperature, when the velocity increases over $0.055 \mathrm{~m} / \mathrm{s}$, the PbLi outlet temperature will be lower than $600{ }^{\circ} \mathrm{C}$, which cannot satisfy the requirement. A temperature decline of $4.02{ }^{\circ} \mathrm{C}$ and $51.51{ }^{\circ} \mathrm{C}$ takes place for tungsten and RAFM, respectively. For the pressure drop variation, there is a peak at the velocity of $0.05 \mathrm{~m} / \mathrm{s}$. Before this peak, the pressure drop increases as velocity increases. This is because the buoyancy-lift-induced vortices dominate in this area, and increasing velocity will enhance the vortices. However, this buoyancy effect will be replaced gradually by forced convection when the velocity is increasing beyond $0.05 \mathrm{~m} / \mathrm{s}$, where the number of vortices decreases, such that less momentum of PbLi flow is lost. The temperature field is shown in Figure 15. It is observed that low velocity will make the temperature distribution uneven, and this unevenness can be alleviated by increasing the velocity. For example, a poloidal temperature difference of $210^{\circ} \mathrm{C}$ occurs in Channel 2 and 3 when the $\mathrm{PbLi}$ flow velocity is $0.03 \mathrm{~m} / \mathrm{s}$, and the resulting temperature gradient will bring stronger buoyancy lift that leads to a larger pressure drop. However, this will diminish as the velocity increases. For instance, the temperature difference for the velocity of $0.09 \mathrm{~m} / \mathrm{s}$ is almost indistinguishable (Figure 15).

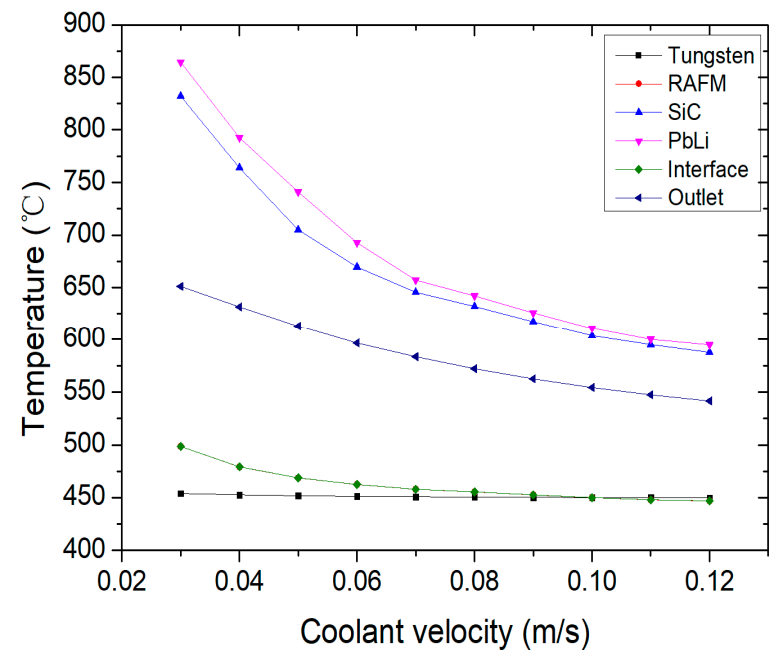

Figure 13. Variation of maximum temperature versus different coolant inlet velocity.

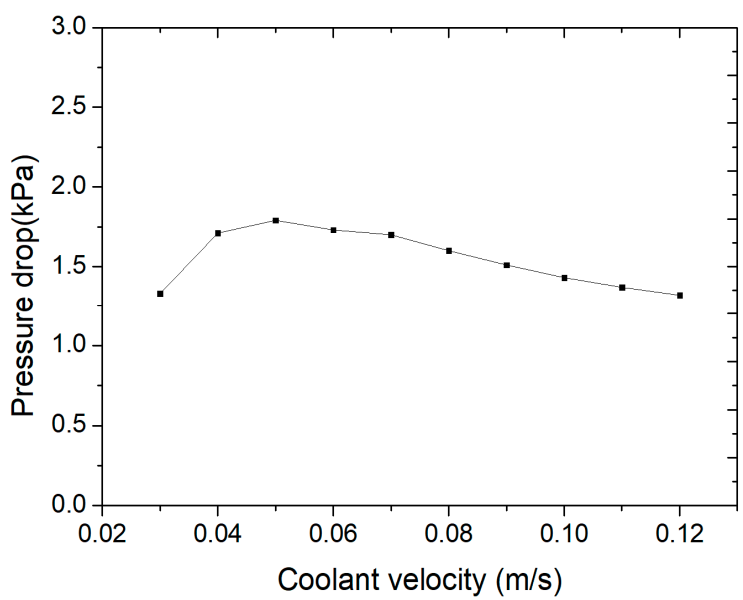

Figure 14. Variation of pressure drop versus different coolant inlet velocity. 


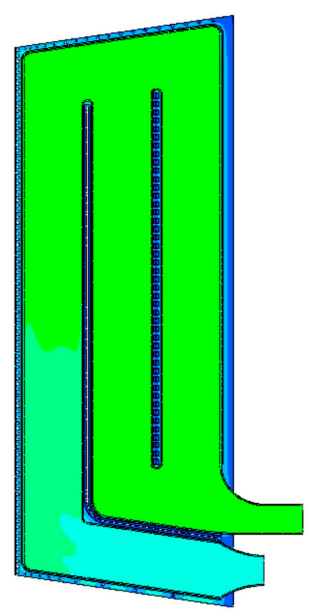

(a)

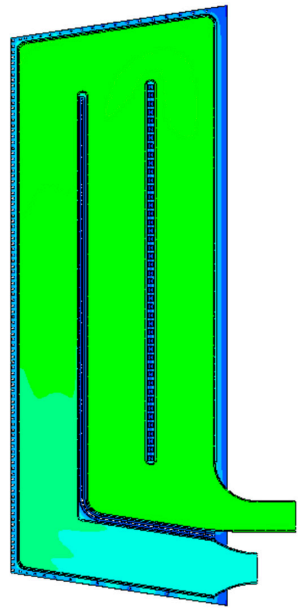

(b)

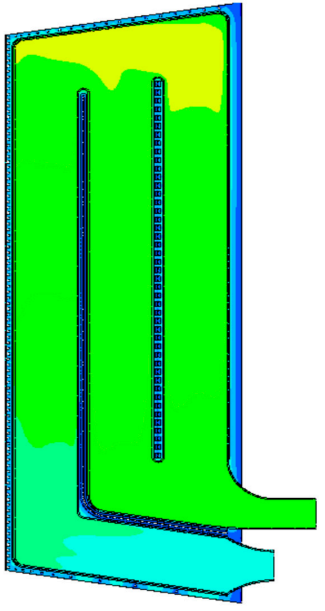

(c)

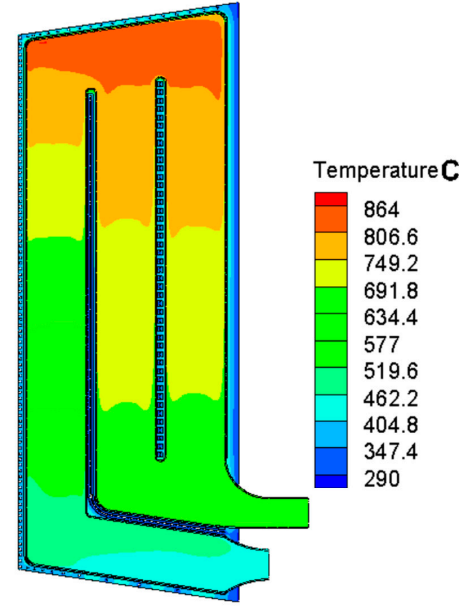

(d)

Figure 15. Temperature field under different coolant inlet velocity (a) $0.09 \mathrm{~m} / \mathrm{s} ;(\mathbf{b}) 0.07 \mathrm{~m} / \mathrm{s} ;(\mathbf{c}) 0.05 \mathrm{~m} / \mathrm{s} ;(\mathbf{d}) 0.03 \mathrm{~m} / \mathrm{s}$.

\subsubsection{Adjustment on the Outlet Temperature}

As mentioned above, the thermal conductivity and coolant inlet velocity have significant effects on the thermal hydraulic performance of the WLLC blanket. The design target of the outlet temperature is $600-700{ }^{\circ} \mathrm{C}$ in order to achieve high power conversion efficiency. These two parameters are adjusted and optimized simultaneously to obtain outlet temperatures of $600{ }^{\circ} \mathrm{C}$ and $700{ }^{\circ} \mathrm{C}$, respectively. As shown in Figure 16, it indicates that the relationship between the velocity of PbLi flow and the TC of SiC is almost linear. Higher TC of $\mathrm{SiC}$ means poorer insulation performance. Thus, a lower velocity is needed to compensate and obtain a satisfactory outlet temperature. Besides, it shows that the design target of the outlet temperature cannot be achieved by adjusting only one parameter. For example, when the $\mathrm{TC}$ of $\mathrm{SiC}$ is greater than $3.5 \mathrm{~W} /(\mathrm{m} \cdot \mathrm{K})$, decreasing the inlet velocity is impossible to sustain outlet temperature $\geq 600^{\circ} \mathrm{C}$, and it needs to improve the insulation of $\mathrm{SiC}$ further. In all scenarios, the $\mathrm{TC}$ of $\mathrm{SiC}=1.0-2.5 \mathrm{~W} /(\mathrm{m} \cdot \mathrm{K})$ can realize the outlet temperature of $700^{\circ} \mathrm{C}$. And when the target outlet temperature is $600^{\circ} \mathrm{C}$, the corresponding $\mathrm{TC}$ of $\mathrm{SiC}$ is $1.0-3.5 \mathrm{~W} /(\mathrm{m} \cdot \mathrm{K})$. Using the $\mathrm{TC}$ of $\mathrm{SiC}$-velocity value pairs corresponding to the outlet temperature of $600{ }^{\circ} \mathrm{C}$ and $700{ }^{\circ} \mathrm{C}$ as boundary points, an "attainable region" is defined, where it is easy to find the possible combination of the PbLi velocity and TC of $\mathrm{SiC}$ to have outlet temperature within the target range. The results of these scenarios are summarized in Table 5, in which all the material temperatures can satisfy the requirements.

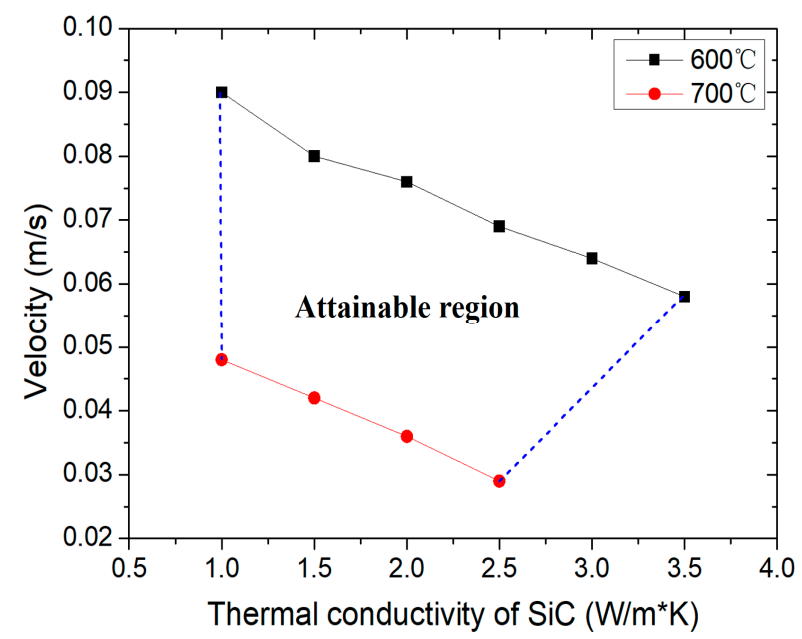

Figure 16. Attainable region for satisfactory outlet temperatures. 
Table 5. Results summary for the selective scenarios.

\begin{tabular}{|c|c|c|c|c|c|c|c|c|c|}
\hline \multirow{2}{*}{$\#$} & \multirow{2}{*}{$\begin{array}{c}\text { TC } \\
(\mathrm{W} / \mathrm{m} \cdot \mathrm{K})\end{array}$} & \multirow{2}{*}{$\begin{array}{l}\text { Inlet Velocity } \\
\qquad(\mathrm{m} / \mathrm{s})\end{array}$} & \multicolumn{5}{|c|}{$\operatorname{Max} . \mathrm{T}\left({ }^{\circ} \mathrm{C}\right)$} & \multirow{2}{*}{$\begin{array}{l}\text { Outlet } \\
\text { T. }\left({ }^{\circ} \mathrm{C}\right)\end{array}$} & \multirow{2}{*}{$\underset{(\mathrm{kPa})}{\Delta P}$} \\
\hline & & & Tungsten & RAFM & $\mathrm{SiC}$ & PbLi & Interface & & \\
\hline 1 & \multirow{2}{*}{1.0} & 0.09 & 448.67 & 441.96 & 637.02 & 637.23 & 432.03 & 600 & 2.29 \\
\hline 2 & & 0.048 & 449.43 & 444.35 & 833.24 & 838.22 & 444.35 & 700 & 3.61 \\
\hline 3 & \multirow{2}{*}{1.5} & 0.08 & 449.06 & 442.30 & 649.03 & 650.86 & 438.38 & 603 & 2.27 \\
\hline 4 & & 0.042 & 450.33 & 455.37 & 825.51 & 836.06 & 455.37 & 700 & 3.35 \\
\hline 5 & \multirow[b]{2}{*}{2.0} & 0.076 & 449.62 & 444.46 & 651.21 & 656.02 & 444.46 & 600 & 2.15 \\
\hline 6 & & 0.036 & 451.50 & 468.01 & 844.71 & 861.78 & 468.01 & 700 & 2.92 \\
\hline 7 & \multirow{2}{*}{2.5} & 0.069 & 450.22 & 450.55 & 656.34 & 665.31 & 450.55 & 600 & 2.05 \\
\hline 8 & & 0.029 & 453.02 & 484.61 & 877.48 & 902.16 & 485.57 & 700 & 2.20 \\
\hline 9 & 3.0 & 0.064 & 450.78 & 457.06 & 665.47 & 681.77 & 457.06 & 600 & 1.90 \\
\hline 10 & 3.5 & 0.058 & 451.37 & 463.90 & 677.09 & 702.97 & 463.90 & 600 & 1.74 \\
\hline
\end{tabular}

\subsection{Structure Optimization}

In the present design of the WLLC blanket, the PbLi flow channels are formed by the two CPs, and the channel width is equally spaced. The typical results (see Section 4.1) indicate that the hotspot would occur at the upper location due to the existing vortices (Figure 6), and this has a negative effect on increasing the outlet temperature. Therefore, the structure optimization is investigated by adjusting the width ratio of PbLi channels in order to change the flow field, then further optimize the temperature field. As shown in Figure 17, the total radial length remains the same, and the other three structures are designed on the basis of the standard model using three ratios, namely, 0.5:1:1.5, 0.5:1.5:1, and 1:0.5:1. Thermal hydraulic analyses are carried out for these optimization designs, and all the boundary conditions remain the same as in the typical case discussed in the previous sections.

The temperature contour with streamlines is shown in Figure 18, and the detailed thermal hydraulic results are summarized in Table 6. In general, compared with Design 1\#, the structural optimizations (Design 2\# and 3\#) have slight effects on the peak temperature of materials, but Design 1\# presents larger poloidal temperature differences and lower outlet temperatures, which causes more vortices in the channels. On the contrary, because the flow velocity in Channel 1 is twice as large, the streamline is smoother, and there are no obvious vortices. However, the flow in Designs 2\# and 3\# will rotate around CP2, which causes a pressure drop of about $27.8 \%$ larger than Design 1. Meanwhile, keeping the width of Channel 1 unchanged, yet reducing the width of Channel 2 by half, there is no large difference of the material temperatures, except for the lower outlet temperature, which is adverse for achieving high power conversion efficiency. From this point of view, although Design 1 has a lower outlet temperature, it still presents better thermal hydraulic performances than the other designs due to the significantly reduced pressure drop. 


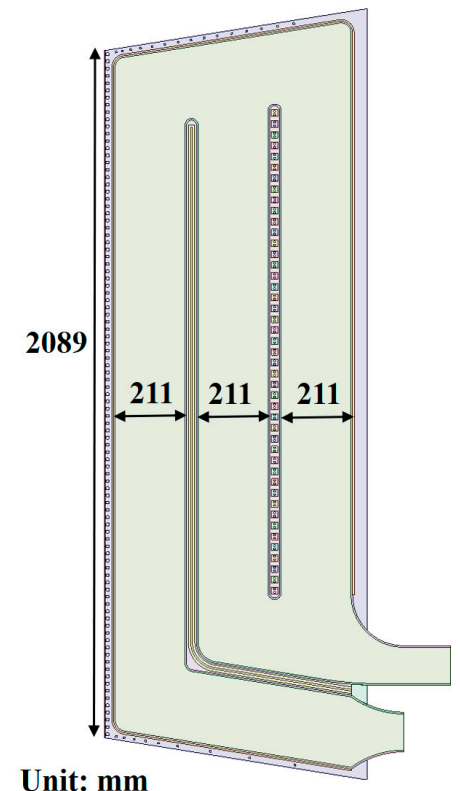

(a)

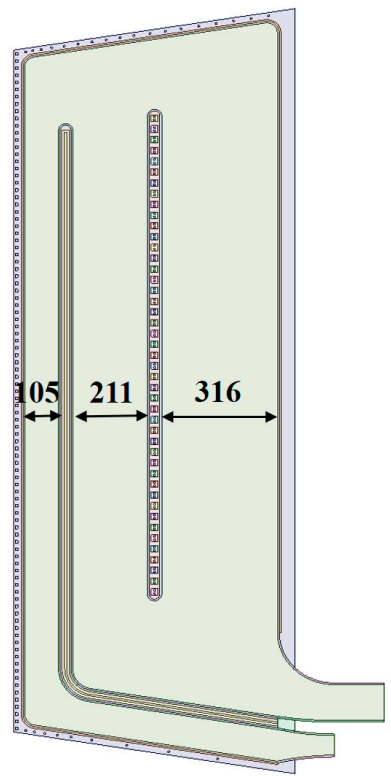

(b)

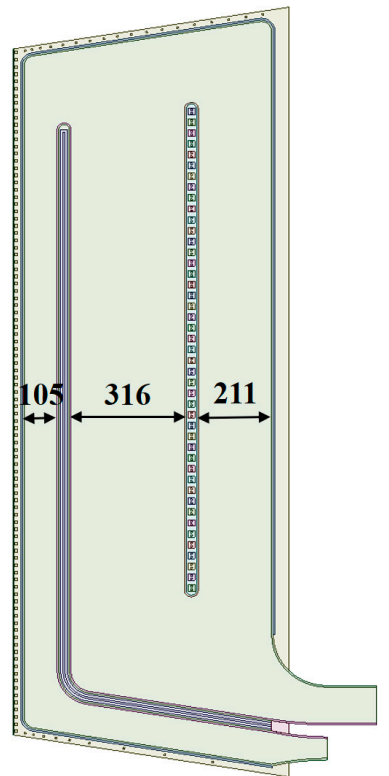

(c)

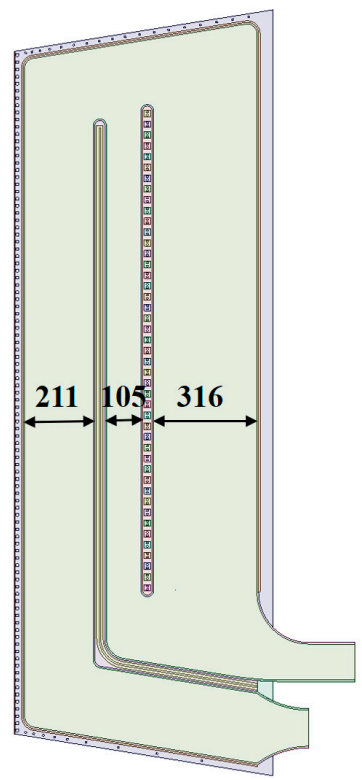

(d)

Figure 17. Three structure designs for optimization (a) 1:1:1; (b) 0.5:1:1.5; (c) 0.5:1.5:1; (d)1:0.5:1.

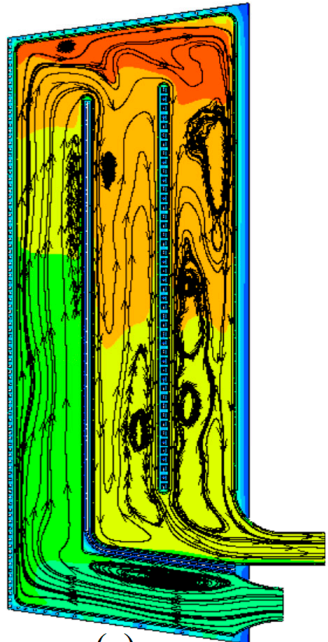

(a)

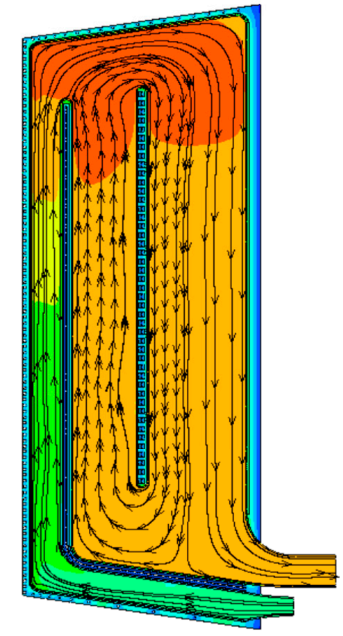

(b)

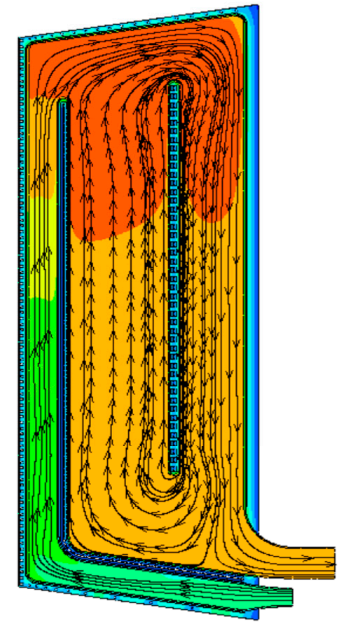

(c)

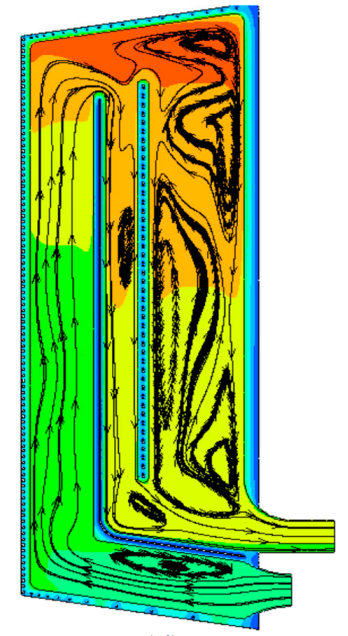

(d)

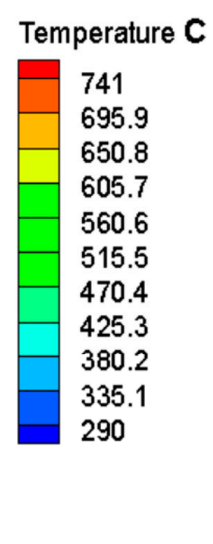

Figure 18. Temperature field combined with streamline (a) 1:1:1; (b) 0.5:1:1.5; (c) 0.5:1.5:1; (d)1:0.5:1.

Table 6. Results summary of the four designs.

\begin{tabular}{|c|c|c|c|c|c|c|c|}
\hline \multirow{2}{*}{ \# } & \multicolumn{5}{|c|}{ Max. $T\left({ }^{\circ} \mathrm{C}\right)$} & \multirow{2}{*}{$\begin{array}{l}\text { Outlet } T \text {. } \\
\quad\left({ }^{\circ} \mathrm{C}\right)\end{array}$} & \multirow{2}{*}{$\begin{array}{c}\Delta P \\
(\mathrm{kPa})\end{array}$} \\
\hline & Tungsten & RAFM & $\mathrm{SiC}$ & $\mathrm{PbLi}$ & Interface & & \\
\hline 1 & 451.82 & 468.83 & 704.89 & 740.95 & 468.83 & 612.85 & 1.79 \\
\hline 2 & 452.27 & 479.96 & 723.76 & 733.7 & 485.75 & 662.94 & 2.31 \\
\hline 3 & 452.25 & 481.65 & 722.40 & 732.52 & 487.50 & 663.73 & 2.34 \\
\hline 4 & 449.82 & 472.95 & 712.94 & 740.85 & 472.95 & 609.74 & 1.70 \\
\hline
\end{tabular}

\section{Conclusions}

The Water Lead Lithium Cooled (WLLC) blanket that adopts pressurized water (15.5 MPa, 285/325 ${ }^{\circ} \mathrm{C}$ ) cooling the structural components, liquid PbLi as breeder and coolant, and $\mathrm{SiC}$ as thermal insulator between $\mathrm{PbLi}$ and the structures is being under development for the Chinese Fusion Engineering Test Reactor. In the present work, the 
thermal hydraulic analysis based on a poloidal-radial slice model is performed for this WLLC blanket design. The analyses results show that the present design can achieve high outlet temperature in the range of $600-700{ }^{\circ} \mathrm{C}$ without material temperatures exceeding the upper limits, which is beneficial for high power conversion efficiency.

A series of sensitivity analyses are conducted with regard to the flow inlet velocity and thermal conductivity of the $\mathrm{SiC}$ insulator. Results indicate that the thermal conductivity of $\mathrm{SiC}$ has a significant influence on the temperature field, streamlines, and pressure drop. It shows that lower $\mathrm{TC}$ of $\mathrm{SiC}$ can maintain the temperature of $\mathrm{PbLi}$ at high level, yet induce unfavorably an increased number of vortices in the liquid PbLi flow as well as a larger pressure drop. On this basis, the joint effects of the TC of $\mathrm{SiC}$ and inlet velocity on the performance of blanket thermal hydraulics are analyzed. Then, using the TC of $\mathrm{SiC}$-velocity value pairs corresponding to the outlet temperature of upper and lower target values as boundary points, a so-called "attainable region" is proposed, where the possible combination of the PbLi velocity and $\mathrm{TC}$ of $\mathrm{SiC}$ are easily identified to ensure the outlet temperature within the design target range.

The structure optimization is further performed by decreasing the width of the front channel to reduce the buoyancy effects at the upper location. Four cases with the width ratio of the three channels being 1:1:1, 0.5:1:1.5, 0.5:1.5:1, and 1:0.5:1.5, are studied. Compared with the 1:1:1 design, although Design 2\# and 3\# can make the temperature field more evenly distributed and reduce obvious local vortices, the flow rotation emerging in these two designs around CP2 would cause a pressure drop that is $27.8 \%$ larger than the 1:1:1 design. Therefore, the present design of the WLLC blanket is still the most reasonable.

Author Contributions: Conceptualization, K.J., L.C. and K.H.; methodology, K.J.; software, K.J., Y.Y. and X.M.; validation, Y.Y.; formal analysis, K.J. and Y.Y.; investigation, K.J.; resources, Q.W. and X.M.; visualization, K.J.; writing, K.J. and K.H.; project administration, S.L. and K.H.; funding acquisition, K.J., S.L. and K.H. All authors have read and agreed to the published version of the manuscript.

Funding: This work is supported by the Comprehensive Research Facility for Fusion Technology (CRAFT) Program of China [Contract No. 2018-000052-73-01-001228], and the Science Foundation of ASIPP [No. DSJJ-2020-10].

Conflicts of Interest: The authors declare no conflict of interest.

\section{References}

1. Wan, Y.; Li, J.; Liu, Y.; Yong, L.; Wang, X.; Chan, V.; Chen, C.; Duan, X.; Fu, P.; Gao, X.; et al. Overview of the present progress and activities on the CFETR. Nucl. Fusion 2017, 57, 102009. [CrossRef]

2. Leys, O.; Leys, J.M.; Knitter, R. Current status and future perspectives of EU ceramic breeder development. Fusion Eng. Des. 2021, 164, 112171. [CrossRef]

3. Frano, R.L.; Puccini, M. Preliminary investigation of $\mathrm{Li}_{4} \mathrm{SiO}_{4}$ pebbles structural performance. Fusion Eng. Des. 2021, 167, 112388. [CrossRef]

4. Smolentsev, S.; Moreau, R.; Abdou, M. Characterization of key magnetohydrodynamic phenomena in PbLi flows for the US DCLL blanket. Fusion Eng. Des. 2008, 83, 771-783. [CrossRef]

5. John, H.; Malang, S.; Sebening, H. KfK Contribution to the Development of DEMO-Relevant Test Blankets for NET/ITER. I: Self-Cooled Liquid Metal Breeder Blanket. Volume 1: Summary; Kernforschungszentrum Karlsruhe: Karlsruhe, Germany, $1991 ;$ pp. 1-67.

6. Wong, C.; Mcquillan, B.W.; Schleicher, R.W. Evaluation of US demo helium-cooled blanket options. In Proceedings of the 16th International Symposium on Fusion Engineering, Champaign, IL, USA, 30 September-5 October 1995.

7. Ramirez, A.P.; Caso, A.; Giancarli, L. Tauro: A ceramic composite structural material self-cooled Pb-17Li breeder blanket concept. J. Nucl. Mater. 1996, 233-237, 1257-1261. [CrossRef]

8. Raffray, A.R.; El-Guebaly, L.; Malang, S. Advanced power core system for the ARIES-AT power plant. Fusion Eng. Des. 2007, 82, 217-236. [CrossRef]

9. Smolentsev, S.; Morley, N.; Abdou, M.; Malang, S. Dual-coolant lead-lithium (DCLL) blanket status and R\&D needs. Fusion Eng. Des. 2015, 100, 44-54.

10. Zeng, Z.; Jiang, J.; Chen, S.; Wang, F. Preliminary neutronics analyses of China Dual-Functional Lithium-Lead (DFLL) test blanket module for CFETR. Fusion Eng. Des. 2020, 152, 111414. [CrossRef]

11. Fernández, I.; Palermo, I.; Urgorri, F.R. Alternatives for upgrading the EU DCLL breeding blanket from MMS to SMS. Fusion Eng. Des. 2021, 167, 112380. [CrossRef] 
12. Del Nevo, A.; Arena, P.; Caruso, G.; Chiovaro, P. Recent progress in developing a feasible and integrated conceptual design of the WCLL BB in EUROfusion project. Fusion Eng. Des. 2019, 146, 1805-1809. [CrossRef]

13. Auber, J.; Aiello, G.; Arena, P. Status of the EU DEMO HCLL breeding blanket design development. Fusion Eng. Des. 2018, 136, 1428-1432. [CrossRef]

14. Martelli, E.; Caruso, G.; Giannetti, F.; Del Nevo, A. Thermo-hydraulic analysis of EU DEMO WCLL breeding blanket. Fusion Eng. Des. 2018, 130, 48-55. [CrossRef]

15. Boullon, R.; Aubert, J.; Aiello, G.; Jaboulay, J.-C.; Morin, A. The DEMO Helium Cooled Lithium Lead "Advanced-Plus" Breeding Blanket: Design Improvement and FEM Studies. Fusion Eng. Des. 2019, 146, 2026-2030. [CrossRef]

16. Li, W.; Tian, W.; Qiu, S.; Su, G.; Jiao, H.; Bai, Y.; Chen, H.; Wu, Y. Preliminary thermal-hydraulic and safety analysis of China DFLLTBM system. Fusion Eng. Des. 2013, 88, 286-294. [CrossRef]

17. Fernández-Berceruelo, I.; Rapisarda, D.; Palermo, I.; Maqueda, L.; Alonso, D.; Melichar, T.; Frybort, O.; Vala, L.; Ibarra, A. Thermal-hydraulic design of a DCLL breeding blanket for the EU DEMO. Fusion Eng. Des. 2017, 124, 822-826. [CrossRef]

18. Ni, W.F.; Qiu, S.Z.; Su, G.H.; Tian, W.X.; Wu, Y.W. Numerical investigation of buoyant effect on flow and heat transfer of Lithium-Lead Eutectic in DFLL-TBM. Prog. Nucl. Energy 2012, 58, 108-115. [CrossRef]

19. Jiang, K.; Ding, W.; Zhang, X. Development of neutronic-thermal hydraulic-mechanic-coupled platform for WCCB blanket design for CFETR. Fusion Eng. Des. 2018, 137, 312-324. [CrossRef]

20. Jiang, K.; Ma, X.; Cheng, X.; Liu, S. Thermal hydraulic analysis on the whole module of water cooled ceramic breeder blanket for CFETR. Fusion Eng. Des. 2016, 112, 81-88. [CrossRef]

21. Jiang, K.; Martelli, E.; Agostini, P.; Del Nevo, A. Investigation on cooling performance of WCLL breeding blanket first wall for EU DEMO. Fusion Eng. Des. 2019, 146, 2748-2756. [CrossRef]

22. Anonymous. Report on the Mechanical and Thermal Properties of Tungsten and TZM Sheet Produced in the Refractory Metal Sheet Rolling Program; Southern Research Institute Report 7563-1479-XII to the U.S. Bureau of Naval Weapons (638631 CE); Southern Research Institute: Birmingham, AL, USA, 31 August 1966.

23. Hirose, T.; Nozawa, T.; Stoller, R.E.; Hamaguchi, D.; Sakasegawa, H.; Tanigawa, H.; Eneoda, M.; Katoh, Y.; Snead, L.L. Physical properties of F82H for fusion blanket design. Fusion Eng. Des. 2014, 89, 1595-1599. [CrossRef]

24. Wong, C.P.C.; Malang, S.; Sawan, M.; Dagher, M.; Smolentsev, S.; Merrill, B.; Youssef, M.; Reyes, S.; Sze, D.K.; Morley, N.B.; et al. An overview of dual coolant $\mathrm{Pb}-17 \mathrm{Li}$ breeder first wall and blanket concept development for the US ITER-TBM design. Fusion Eng. Des. 2006, 81, 461-467. [CrossRef]

25. Martelli, E.; Del Nevo, A.; Arena, P.; Bongiovi, G.; Caruso, G.; Di Maio, P.A.; Eboli, M.; Mariano, G.; Marinari, R.; Moro, F.; et al. Advancements in DEMO WCLL breeding blanket design and integration. Int. J. Energy Res. 2018, 42, 27-52. [CrossRef]

26. Stankus, S.V.; Khairulin, R.A.; Mozgovoi, A.G. An experimental investigation of the density and thermal expansion of advanced materials and heat-transfer agents of liquid-metal systems of fusion reactor: Lead-lithium eutectic. High Temp. 2006, 44, 829-837. [CrossRef] 